\title{
Universal Installation for the integrated utilization of flue gases and wastewater from thermal power plants
}

\author{
Sergey A. Glazyrin ${ }^{1}$, Mikhail G. Zhumagulov ${ }^{1, *}$, Zhanar A. Aydimbaeva ${ }^{2}$, and Abay M. Dostiyarov ${ }^{2}$ \\ ${ }^{1}$ L.N. Gumilyov Eurasian National University, Dept. of Power engineering, 2 Satpayev str, 010003 Nur-Sultan, Kazakhstan \\ ${ }^{2}$ Almaty University of Power Engineering and Telecommunications, Dept. of Power engineering, 050013 Baytursynuly, 126/1, Almaty \\ c., Kazakstan
}

\begin{abstract}
For 30 years research has been carried out on the use of wastewater from thermal power plants and industrial boilers, as well as on the use and extraction of various components from flue gases such as carbon dioxide, sulfur and nitrogen. Technological solutions were developed and implemented in various productions at various times: - use of acid-forming components of flue gases for the regeneration of cation exchangers; - carbon dioxide from flue gases of $99.9 \%$ purity with "food" quality; - technical nitrogen of 95-99 purity from flue gases; - wastewater usage to increase the degree of sulfur oxides from flue gases. The article presents a technological solution for the integrated utilization of flue gases and wastewater from a thermal power plant with high-pressure boilers burning solid fuels.
\end{abstract}

\section{Introduction}

The main process of water treatment used in boilers is the technology using ion-exchange materials, which require periodic regeneration. In accordance with the increase in the production of desalted and softened water, more and more reagents are spent on the regeneration of ion exchangers.

For the regeneration of cation exchangers, solutions of sodium chloride or sulfuric acid are usually used. The costs of obtaining these reagents are increasing every year and it is getting difficult to obtain them, and sodium chloride is used in other industries, primarily for the production of caustic soda, chlorine and other substances.

Under these conditions, it is relevant to search for new low-cost and non-deficient reagents for the preparation of regeneration solutions and to develop technologies for water preparation and regeneration of ion exchangers that save already known reagents [1].

The process of using carbon dioxide in the production of electric welding at enterprises is improved year by year. When performing welding in a carbon dioxide environment, the quality of the weld is significantly higher than when using coated electrodes as the wire is used instead of the electrode. In addition, labor productivity during welding is increased by $2.5-4$ times. Carbon dioxide is also required in the food industry

At the same time, the outgoing flue gases contain carbon dioxide, the production of which does not pose a great deal of difficulty for enterprises that have thermal power units [2].
In this regard, it is of interest to consider the possibility of using carbon dioxide for the preparation of regeneration solutions, which would make it possible to have the necessary amount of reagents of our own production.

For the preservation of heat and power equipment during idle time, the nitrogen preservation method is used, which is the simplest and most reliable way to protect against corrosion [3]. However, the method has not yet widely used in the energy sector due to the large capital expenditures on the construction of typical nitrogen-oxygen plants and the considerable costs of their maintenance. Therefore, obtaining cheap nitrogen at its own enterprise is also of current interest. In addition, the issue of using nitrogen to de-aerate the feedwater of boilers, in order to displace oxygen from water, in water-heating boilers, is being worked out, which, with a positive result, will allow us to avoid evacuation of the deaeration process.

Flue gases contain acidic components, which allows them to be used to neutralize alkaline waste water $[4,5]$. If we technologically combine neutralization with the carbon dioxide production scheme, then, by taking off the flue gases after the neutralization unit, we get the gas almost completely purified from sulfur components.

Thus, the flue gases of industrial and power boilers are raw materials for the production of products used not only in the energy sector, but also in other industries.

\section{Research methods}

General scientific, empirical, theoretical methods and experiments on laboratory and industrial equipment were used in the study on the development of technology for

Corresponding author: zhumagulov mg@enu.kz 
the integrated utilization of flue gases and wastewater from thermal power plants and boiler houses of industrial enterprises [6].

\section{Results and discussions}

For the extraction of individual components and their mixtures from exhaust gases, which are used in various industries, there are developments of installations for the production and use of these components, which have passed pilot tests for a long time, or are currently under operation. These are installations for the production of carbon dioxide, nitrogen, the preparation of regeneration solutions, the usage of acidic components of flue gases to neutralize alkaline waste water. Any enterprise with a boiler house needs: carbon dioxide - for electric welding; nitrogen - for preservation in TPPs or for grain storage at an industrial district boiler house; acid components - for preparing regeneration solutions. But installation of several separate installations in one enterprise is economically and technologically inefficient.

A universal installation was developed, which allows producing several types of products in one production using current developments [7]. Such an installation should not have high performance in obtaining individual components, but sufficient to meet the needs of not only the production itself, but also a small city. Part of the production, such as carbon dioxide and nitrogen, can be realized on the side. Low productivity is also explained by the fact that this installation cleans the flue gases, improving the environment, does not require a large staff, is mobile in operation, and should be planned separately at each enterprise, making the most of the existing space and equipment.

The following results were obtained based on the results of industrial tests

A flow chart for the preparation of regeneration solutions using exhaust flue gases, presented in Figure 1, has been developed. Studies have been conducted on the use of the solutions obtained in a water treatment unit for the regeneration of cation-exchange filters [8].

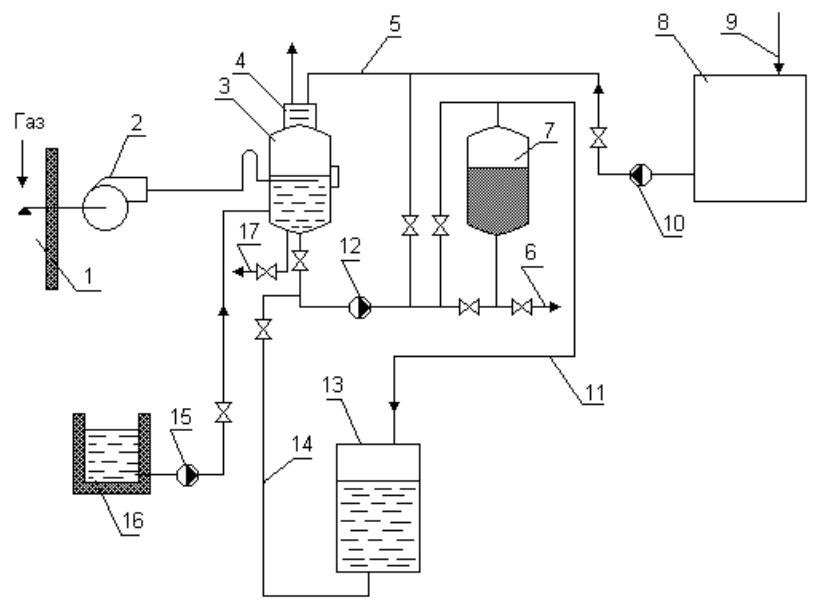

Fig. 1. Recovery scheme of using the regeneration solution for its reuse and disposal of flue gases (1 -flue-gas duct; 2 - fan; 3 - regeneration solution preparation tank; 4 - deaerator head; 5 - line for recirculation of the solution in the filter; 6 - supply of the regeneration solution to the filter; 7 - cation filter; 8 collection tank of alkaline waste water from water treatment; 9 - alkaline water collection line during regeneration of anionexchange filters; 10, 12 - pumps; 11 - discharge line of the regeneration solution for reuse; 13 - tank for receiving discharge of regeneration solution; 14 - supply line of spent regeneration solution for the preparation of a fresh solution; 15 - salt feeding pump; 16 - salt storage cell; 17 -drainage).

Based o the results of the study conducted we can note the following:

1. The regeneration solutions have the following composition at different $\mathrm{pH}$ values:

- at $\mathrm{pH}=1-\mathrm{H}_{2} \mathrm{SO}_{4}$ to 0.1 g-mol $/ 1$ and trace amounts of $\mathrm{H}_{2} \mathrm{SO}_{3}$;

- at $\mathrm{pH}=2-\mathrm{H}_{2} \mathrm{SO}_{4}$ to $0.03 \mathrm{~g}$ - $\mathrm{mol} / 1, \mathrm{H}_{2} \mathrm{SO}_{3}-0.05$ $0.08 \mathrm{~g}-\mathrm{mol} / \mathrm{l}$ and trace amounts of $\mathrm{HNO}_{3}$ and $\mathrm{HNO}_{2}$.

Small amounts of $\mathrm{V}, \mathrm{Ba}, \mathrm{Ti}$, and other heavy metals were detected in solutions, which in aqueous solution can be catalysts for the oxidation of $\mathrm{SO}_{3}{ }^{2-}$ and $\mathrm{SO}_{3}{ }^{2-}$ and $\mathrm{HSO}_{3}{ }^{-}$in $\mathrm{SO}_{4}{ }^{2-}$ by the reaction

$$
\mathrm{H}_{2} \mathrm{SO}_{3}+1 / 2 \cdot \mathrm{O}_{2} \rightarrow \mathrm{H}_{2} \mathrm{SO}_{4}
$$

which explains the high concentration of $\mathrm{H}_{2} \mathrm{SO}_{4}$ and the practical absence of dissolved oxygen.

2. Using flue gases in heating boilers, TPP, it is possible to prepare regeneration solutions with $\mathrm{pH}=1$. These solutions effectively replace the salt solutions that are currently used for regeneration. The degree of regeneration of the solution with $\mathrm{pH}=1$ reaches 60 $70 \%$, which will save a large number of reagents.

3. The following is effective: regeneration by countercurrent, temperature is $20-40{ }^{\circ} \mathrm{C}$, transmission rate of the solution $15-20 \mathrm{~m} / \mathrm{h}$. The ratio of the volume of the regeneration solution to the volume of sulfougol is $10-15$

4. The regeneration solution can be reused after the new portion of the flue gas is saturated. The multiplicity of such use is 5-7, without precipitation and reducing the regeneration properties. This reduces the water consumption for regeneration. The reduction of water consumption is also facilitated by the fact that regeneration can be carried out without preliminary loosening, and 2-3 times less water is used for washing cationite after regeneration

5. High efficiency shows joint regeneration with a solution of $\mathrm{NaCl}$ with a concentration of $2 \%$ and a solution of flue gases. When this is carried out $\mathrm{H}-\mathrm{Na}$ cationization. At $30 \%$ salt saving, a high degree of regeneration of the cation exchanger is reached (up to 90-95\%) and the content of the $\mathrm{HCO}_{3}{ }^{-}$ion decreases, which prevents alkaline corrosion in the boilers.

A universal installation for thermal power plants with high-pressure boilers was developed, shown in Figure 2 [9]. 


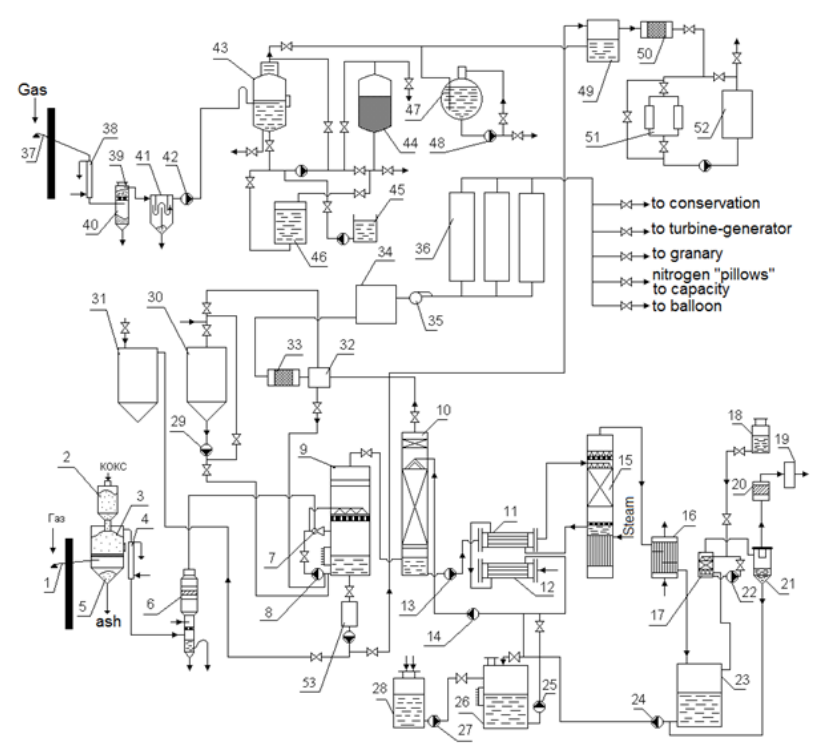

Fig. 2. Universal installation for thermal power plants with high pressure boilers ( 1 - high-temperature gas extraction unit; 2 - coke stock capacity; 3 - reactor; 4, 38 - tube-in-tube type heat exchanger; 5, 40 - ashpit; 6 - gas cooler; 7 - low-pressure ejector; 8 - circulation pump of soda solution; 9 - soda scrubber; 10 - absorber; 11 - heat exchanger MEA - MEA; 12 heat exchanger MEA - water; 13, 14, 22, 24, 25, 27, 29, 48 the pump; 15 - desorber; 16 - vapor-gas cooler; 17 - site washing of carbon dioxide with manganese-acid potassium; 18 - capacity of preparation of manganese-acid potassium; 19 carbon dioxide gas tank; 20 - carbon dioxide moisture desiccant; 21 - droplet separator; 23 - condensate separator; 26 - tank for preparation of MEA working solution; 28 - storage capacity of a concentrated solution of MEA; 30 - tank for collecting acid waste water from the chemical water treatment; 31 - tank collection of alkaline waste water from the chemical water treatment; 32 - alkaline barrier filter; 33 - Nitrogen moisture dryer; 34 - nitrogen gas tank; 35 - compressor; 36 receiver; 37 - low temperature gas extraction unit; 39 - filter for removal of mechanical suspension; 41 - bulk ash collector; 42 - fan; 43 - capacity of the preparation of the regeneration solution; 44 - sodium - cation filter; 45 - salt storage capacity; 46 - regeneration water collection tank; 47 - boiler drum; 49 barrier soda filter; 50 - dehumidifier of moisture of flue gases used to prepare the regeneration solution;; 51 - node with absorbers loaded with activated carbon; 52 - vegetable storehouse with gas medium; 53 - intermediate tank).

After the high-temperature gas extraction unit 1, a reactor 3 is installed with a coke-2 storage capacity. The reactor produces low-temperature afterburning of oxygen residues from flue gases. Oxygen from flue gases is removed when gases pass through a layer of reducing agent (usually carbon). The interaction of carbon with an oxidizer proceeds with the participation of intermediate unstable formations. It is recommended to use low-ash fuel as a reducing agent, since a ash shell of smaller thickness forms on pieces of low-ash fuel, than on pieces of high-ash fuel. Combustion takes place at a temperature below the melting point of the ash, which does not affect the rate of burning of the particle

The gas extraction unit provides for isolation of the gas extraction pipe from the heating surface of the boiler in order to preserve the temperature of the gas to be extracted. In addition it should be noted that with different modes of operation of the boiler, the temperature of the gas entering the layer of reducing agent must not be lower than the calculated one (for coke it is $600{ }^{\circ} \mathrm{C}$ ). Moreover, the sampling device must exclude additional oxygen suckers with flue gas entering the reactor 3 [10].

In order to sharply reduce the velocity of the gas, the area of the inlet of the probe should be 3-4 times as large as the area of the pipeline that takes gas from the furnace. With a decrease in speed and a change in the direction of motion, large dust particles "fall through" and do not fall into the probe.

The lower part of the reactor ends with an ash storage bin 5 . The gases cleaned with 95 to $98 \%$ of the ash pass through a tube-in-tube heat exchanger, where they are pre-cooled, and sent to the gas cooler 6 , in which they are freed from ash residues discharged through the bottom of the cooler periodic purging, as well as from the vast majority of sulfur components gases. Then the gas is sent to the carbon dioxide production unit.

Gas is taken into the nitrogen receiving unit from the upper part of the absorber and sent to the alkaline barrier filter 32 , in which, due to the constantly flowing alkali from the tank 30 or directly from the alkali discharge pipeline from the water treatment plant, carbon dioxide remains are connected. After the barrier filter, the gas passes through a desiccant of nitrogen 33 , which is filled with silica gel or zeolite, capable of absorbing moisture in the amount of $20 \%$ and $50 \%$ of its own weight, respectively. Nitrogen is sent to the gas tank 34, where, if necessary, the compressor 35 can be pumped out through the receivers 36 to the consumer. The alkali used in the filter 32 is periodically discharged to the suction of the soda-water circulation pump. The nitrogen obtained in the universal installation can be used for the conservation of power equipment, in grain storage facilities, in the turbogenerator, and pumped into cylinders [11].

At thermal power plants that have cation-resin and anion-exchange filters in make-up water preparation system, the project provides for a neutralization unit, in which two tanks 30 and 31 are included to collect waste alkaline water and waste acid after regeneration of filters [12]. In the neutralization unit, small tanks and pumps of various capacities are installed, which can be used in the universal installation, where one of the tanks (30) is designed to collect waste alkaline waters, and the second (31) - for waste acidic waters [13]. If necessary, the alkaline water is pumped into the soda scrubber by pump 29. After a short period of time, $\mathrm{NaOH}$ is transferred to $\mathrm{Na}_{2} \mathrm{CO}_{3}$ under the influence of carbon dioxide and subsequently used to trap residual sulfur from flue gases. The spent soda solution is discharged into the intermediate tank 53, where, if necessary, it is sent to an acid waste collection tank 31 or to a barrier soda filter 49.

For the second part of the installation, where oxygen removal is not required, low-temperature gas extraction by the probe 37 installed behind the exhauster along the gases from the boiler is carried out. Gases are sent to the heat exchanger 38 of the "pipe in pipe" type, where they are cooled with water, which reduces the volume of gases and allows the use of the fan 42, designed for 
lower temperatures and lower performance. When solid fuel is used at TPPs, a filter 39 is installed with anthracite loading to trap suspended particles and ash. An ashpit 40 is mounted in the lower part of the filter. A volumetric ash trap 41 is installed in front of the fan 42 to trap the remaining ash. To prepare the regeneration solution using the acidic components of the flue gases in the tank 43 , the solution is recirculated by the pump. The source water from the recovery water collection tank 46 is removed by the recirculation pump and, after preparing the solution, the ready regeneration solution is supplied by the same pump for the regeneration of the sodium-cation filter 44 . It is desirable to use one of the water treatment filters as the tank.

The gases leaving the deaerator head of the tank 43 do not contain sulfur components or contain them in a minimum quantity and are suitable for use as a source gas for preparing the wash solution when starting blocks from a cold state, as well as for washing copper deposits from the surface of the equipment. The rest of the gases are sent to a barrier soda filter 49 filled with a special solution. The purified gases pass through the dehumidifier of moisture 50 and enter the vegetable storehouse 52, or preliminarily pass the unit 51 with absorbers loaded with activated carbon to regulate the composition of the gas.

When the installation is placed at TPPs, the main units are mounted in the project room of the neutralization unit, at the water treatment plant, in the boiler room, in the area of smoke exhausters [14]. Compressors are mounted in a separate room, gasholders and receivers - outdoors.

A gas extraction unit was designed with lowtemperature oxygen removal in the reductant layer and ash removal.

For the selection of gas from the boiler, it is important to choose the installation location of the selected probe [15]. It should be taken into account that at different loads of the boiler operation, the temperature of the gas entering the layer of reducing agent should not be lower than the calculated one, for example, for coke $600^{\circ} \mathrm{C}$. In addition, the sampling device should exclude additional oxygen suckers with flue gas entering the reactor. The gas extraction unit (Figure 3) includes a bleed probe mounted on the end of the flue gas bleed pipeline.

The probe inlet should be $3-4$ times the area of the extraction pipeline, in order to sharply reduce the velocity of the gas. With a decrease in the velocity and direction of gas movement, large dust particles "fall through" and do not fall into the probe. The inlet of the probe is directed "along the" selected flue gas. With the chosen dimensions and location of the probe, the amount of ash taken into the installation decreases by $20-30 \%$ already in the furnace at the entrance to the probe. The gas extraction pipeline from the furnace is mounted with a slope of at least $15 \%$ towards the reactor, which prevents its ash from being carried.

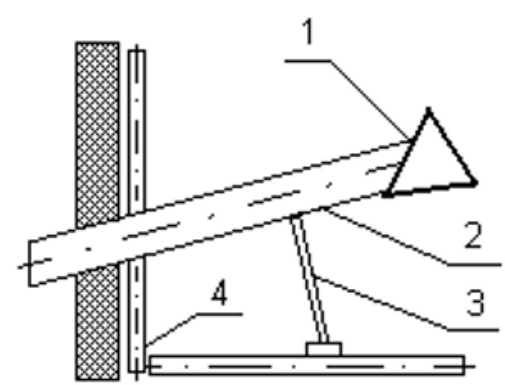

Fig. 3. Gas extraction unit ( 1 - bleed probe; 2 - gas bleed pipeline; 3 - support tube; 4 - heat surface).

When creating the first industrial unit, the ash from the flue gas was removed before it entered the reducing agent layer in the reactor. Various options were tested for ash collectors with bulk separation, with a layer of ceramics and with the installation of cyclone separation inside the ash collector. However, these ash collectors proved to be ineffective in removing ash (up to $75 \%$ ), while at the same time their high hydraulic resistance (from 15.0 to $20.0 \mathrm{kPa}$ ) sharply reduced the gas flow rate for the installation [15]. The ash collectors installed before the reactor could not completely eliminate the drift of the semi-coke layer by fly ash from the flue gases. All ash traps installed in front of the reactor, in spite of their good thermal insulation, reduced the temperature entering the flue gas reactor by an additional 100-200 oC. In addition, when the reactor was heating up, the gas flow rate increased and, as a result, there was an increased drift of the semi-coke layer already in the first 2 to 3 hours after the unit was put into operation.

In the final installation, the main part of the ash was removed in a ash collector mounted under the reactor grate, and for the remaining ash, a volume separation ash collector was installed according to the scheme in the low temperature zone $110-120^{\circ} \mathrm{C}$, which also had a positive effect on the ash removal process.

The rector operates at a temperature of $400-700^{\circ} \mathrm{C}$ and differs in shape, size, ash collectors under the grate, presence of a reducing agent hopper and a water cooling "jacket". The reactor of circular section (Figure 4) is made with a ratio of the height of the layer of reducing agent to the diameter of at least 2 .

There is a repair hatch with a diameter of $500 \mathrm{~mm}$ and a hatch for "hiding" the hot layer of the semi-coke on the grate in its side wall. The thermal insulation of the walls of the reactor both inside and outside is provided. The reducing agent stock, designed for its additional loading on more than once every 2 months is installed above it. An ashpit is located under its grate. The housing of the ashpit and the reactor is made of a single pipe and is insulated from the outside and the inside. The combustion grate was made in two versions. First version was made of stainless steel sheet with a thickness of $10 \mathrm{~mm}$, with holes of $8 \mathrm{~mm}$ diameter and thermal insulation protection from the reductant. However, it showed low reliability during operation. The removal of ash from the reactor was a significantly difficult: the "rubbling" was difficult due to the rough surface of the grid insulation, some of the holes were clogged with small pieces of semi-coke, preventing the 
ash from being removed. Second version of the grate was made of stainless steel tubes with a diameter of 16 $\mathrm{mm}$, with a gap of $6-7 \mathrm{~mm}$, which were fastened by welding to a corner welded to the reactor vessel.

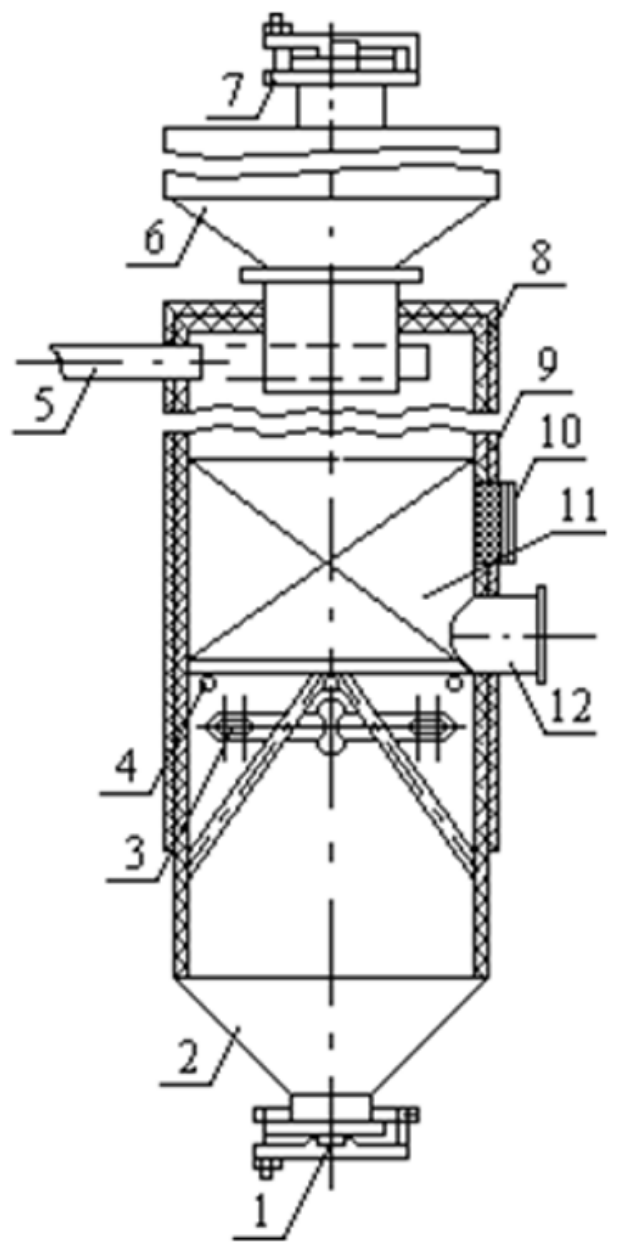

Fig. 4. Reactor ( 1 - ash discharge door; 2 - ash extraction retainer; 3 - gas supply pipeline to the reactor; 4 - combustion grate; 5 - selection of gas from the reactor; 6 - stock bunker for semi-coke; 7 - loading hatch; 8 - heat insulation; 9 - reactor vessel; 10 - repair hatch; 11 - semi-coke loading; 12 - hatch for cleaning the grate).

Five transversely packed stainless steel pipes with 50 $\mathrm{mm}$ in diameter were welded in the bottom of the grate, which served as its support. Simplicity of a design and installation provided reliability at operation. The main disadvantage is the necessity of periodically "rubbling" the reducing agent through the open hatch. The variant of the "swinging" grate was used to clean it from ash, i.e. the handle, mounted on the outside of the reactor, can be "pumped out" by opening the hatch cover. However, there is the problem of sealing grate sites in order to eliminate air suction in the reactor operating under vacuum. When choosing a design variant of the grate, it was taken into account that the frequency of "rubbling" of the layer of reducing agent above the grid is no more than $4-8$ hours, the duration of the operation is $10-15$ minutes.

\section{Conclusions}

The process flow diagram of the universal installation has been developed, which makes it possible to comprehensively utilize wastewater and flue gases at one thermal power plant, burning coal, and to receive several types of products, and to solve simultaneously several tasks, such as:

- regeneration of cation in make-up water preparation system byh regenerated solution prepared with the part of the washing water of cation-exchange filters saturated with acid-forming components of flue gases;

- production of carbon dioxide of food quality from the flue gases, which can be used both for the preparation of carbonated beverages and for welding, etc.

- production of technical nitrogen from flue gases of very high purity, which can be used for equipment conservation, for improving the quality of grain storage and other needs.

\section{References}

[1] S.A. Glazyrin, N.S. Glazyrina, B.G. Mukanova, Multiparametric Optimization of Water Treatment Process for Thermal Power Plants, ICCSAM 2015: 17th International Conference on Computer Science and Applied Mathematics, Venice, Italy, 13-14 April, 328-333 (2015)

[2] S.A. Glazyrin, A.I. Glazyrin, B.K. Aliyarov. Low-performance carbon dioxide plant. Scientific notes of Pavlodar State University (1998). ISBN: 1560-6120

[3] S.A. Glsazyrin, H. Hatjan, Analysis of metal protection methods for equipment of AstanaEnergy JSC against corrosion, V International scientific conference: Actual problems of transport and energy, Astana, 438-441 (2017)

[4] N. Zlatov, S. Glazyrin, M. Zhumagulov, Z. Aidynbayeva, Wastewater treatment of the thermal power plants for desulfurization of flue gas, 2019 International Conference in Telecommunications, Informatics, Energy and Management (TIEM), Kavala, Greece, 12-14 September, 164-167 (2019). ISSN: 2367-8437

[5] S.A. Glazyrin, R.A. Musabekov, N.V. Zlatov, Zh.A. Aidymbayeva, Analysis of technologies for cleaning smoke gases from thermal power plants from sulfur oxides, XXIII Scientific Conference Energy, ecology, comfort, well-being, Sofia (Bulgaria), 29-32 (2018)

[6] Yu.N. Kolmogorov, A.P. Sergeev, D.A. Tarasov, S.P. Arapova, Methods and means of scientific research: textbook (Ekaterinburg: Publishing House Ural, 2017)

[7] S.A. Glsazyrin, N.S. Glsazyrina, Design of a universal installation for the disposal of flue gas components of boiler houses with low pressure boilers, International Scientific Conference 
Problems and Achievements in Industrial Energy, Yekaterinburg (Russia), 74-77 (2010)

[8] S.A. Glsazyrin, Investigation of the properties of cation exchanger during repeated regeneration by a solution prepared on the basis of waste wash water using flue gas components, Herald of PSU (Pavlodar), 2, 58-63 (2008)

[9] S.A. Glsazyrin, Universal installation for the use of flue gas components at thermal power plants with high pressure boilers, Kaz. GOSINTI, order no. 111 (1998)

[10] S.A. Glsazyrin, Design of a flue gas sampling unit for boilers to use their components. International Scientific Conference Current State and Prospects for the Development of Energy, Tashkent (Uzbekistan). 18-20 December, 134136 (2006)

[11] S.A. Glsazyrin, A. Kyrykbay, K.Sh. Erzhanov, Analysis of existing methods for reducing and cleaning sulfur and nitrogen oxide emissions. International Scientific Conference of Young Scientists "XII Satpayev Readings", Pavlodar 21, 70-76 (2012)

[12] S.A. Glsazyrin, A.T. Seitbekova, The process of improving the water treatment process in the boiler, VII International Scientific Conference: Actual problems of transport and energy, Astana. 504-511 (2019)

[13] S.A. Glsazyrin, N.S. Glsazyrina, Problems of operation of existing design schemes for water treatment for supercritical boilers, Herald of PSU, Pavlodar, 2, 73-82 (2017)

[14] S.A. Glsazyrin, A.I. Glsazyrin, Installation for the production of nitrogen from flue gases, Kaz. GOSINTI, Order no. 102,103, 104 (1998)

[15] S.A. Glsazyrin, Options for the integrated use of waste TPP, International scientific conference: Quality of education: management, credit system of education, achievements, problems, 213-215 (2006) 